\title{
LA CRUZ ALZADA DE LA HERMANDAD SACRAMENTAL DE LA PARROQUIA DE SAN JUAN DE MARCHENA
}

\section{THE CROSS OF THE SACRAMENTAL BROTHERHOOD OF THE PARISH OF SAN JUAN OF MARCHENA}

\author{
Antonio Joaquín Santos Márquez \\ Universidad de Sevilla, España \\ anjo@us.es
}

\begin{abstract}
En este artículo se da a conocer el autor de una pieza manierista de calidad, la cruz alzada de la Hermandad Sacramental de la parroquia de san Juan Bautista de Marchena, obra de Antón del Castillo labrada en 1602.

Palabras clave: platería, Sevilla, Manierismo, cruz, Marchena.
\end{abstract}

This paper discloses the author of a mannerist quality piece, the cross in the sacramental brotherhood of the parish of St. John Baptist of Marchena, a work by Anton del Castillo done in 1602.

Keywords: silverwork, Seville, Mannerism, cross, Marchena.

Para conocer la creatividad de la platería sevillana del Manierismo se hace necesaria la documentación, ya que existe una total ausencia de marcas entre los años finales del siglo XVI y gran parte del siglo XVII. En este sentido, los protocolos notariales son fundamentales, ya que de ellos se pueden extraer numerosos datos que nos permiten conocer diferentes aspectos sobre este arte, desde la vida de sus artistas hasta la autoría de muchas obras conservadas. Y esto último es lo que sucede con una pieza de calidad artística, que hasta hoy guardaba celosamente su anonimato, y que gracias a la aparición del concierto de su hechura, podemos concretar su autor y cronología. Nos referimos a la cruz alzada de la Hermandad Sacramental de la parroquia de san Juan Bautista de Marchena ${ }^{1}$.

${ }^{1}$ Esta obra ha sido recogida y estudiada en VVAA.: Inventario artístico de Sevilla y su provincia. Vol II, Madrid, 1985, p. 36; RAVÉ PRIETO, José Luis: "Cruz alzada", en 
El encargo tuvo lugar el 8 de mayo de 1602, cuando el presbítero Luis Ximénez, mayordomo de la Hermandad Sacramental, escrituraba su conveniencia en Sevilla con el platero Antón del Castillo ${ }^{2}$. Un orfebre que, en este mismo año, también trabajó para esta parroquial en la restauración de la custodia de asiento que, veinticinco años antes, había labrado Francisco de Alfaro, y posiblemente, por su buen hacer y su adecuación al gusto del momento, esta Cofradía lo eligió para este nuevo trabajo ${ }^{3}$. Lo estipulado en el contrato era la hechura de una cruz de plata dorada ornamentada "toda con unos ovalos esmaltados", lo cual pone de manifiesto su perfecta adecuación al ejemplar conservado. Su peso debía rondar los nueve marcos de plata, esto es, los dos kilogramos de plata aproximadamente, y de altura debía alcanzar las tres cuartas, o lo que sería lo mismo, los noventa centímetros que hoy día presenta, ya que, según esta conveniencia, el platero se debía hacer cargo de cualquier tipo de aumento que hiciere en la obra, algo que sin duda no se produjo ya que iba en su propio perjuicio. Para el inicio de su trabajo recibió en este mismo acto cuatrocientos reales en escudos de oro, estipulándose además que una vez acabada la obra, fijada para la festividad del Corpus Christi de este mismo año, sería tasada por expertos y valorada la hechura en cinco ducados el marco.

Y sin duda, el acuerdo se llevó a buen puerto, y la cruz finalmente encabezó la referida procesión de 1602. Una pieza que rezuma esa elegancia, equilibrio, geometría y medida propia de lo mejor de la platería manierista de estos años, cuyos rectores, Merino y Alfaro, habían dejado en sus obras maestras de la Catedral hispalense el mejor de los ejemplos. Bien es verdad, tal y como sucede en este mismo caso, que la documentación no especifica si fue el mismo platero el que realizó su "traza y modelo", o por el contrario fue impuesta por el comitente, quien en ocasiones traía un proyecto ejecutado por un reputado artista, habitualmente el maestro catedralicio del momento. Sea como fuere, lo que sí queda claro es la calidad del artista que materializó este bello ejemplar de cruz procesional del Manierismo sevillano.

La cruz sigue el tipo merinense, de brazos rectos y extremos ovales, muy parecido al ejemplar de Monesterio, labrado por Francisco de Alfaro en 1597 . E igual que éste, utiliza los grandes botones de esmalte azul como adorno, tanto en los rectángulos que cubren dichos brazos, como en los óvalos que los rematan,

Tantum ergo sacramentum. Fe, arte y cultura en Marchena. Marchena, 2011, p. 56

${ }^{2}$ Archivo Histórico Provincial de Sevilla. Sección de Protocolos Notariales de Sevilla (a partir de este momento AHPSe. SPNSe.): Legajo 2422, oficio 4, libro $1^{\circ}$ de 1602 , ff. 555 vuelto-557 vuelto.

${ }^{3}$ RAVÉ PRIETO, Juan Luis: Arte religioso en Marchena. Siglos XV al XIX. Marchena, 1985, p. 39.

${ }^{4}$ SANZ, María Jesús, SANTOS, Antonio: Francisco de Alfaro y la renovación de la platería sevillana en la segunda mitad del siglo XVI. Sevilla, 2013, pp. 133-136. 
además de mostrar a su alrededor una fina incisión de foliáceas, típica de estos años. Su pertenencia a la Sacramental queda patente en el crucero, con un medallón en el crucero donde se reproduce en relieve un cáliz y la Sagrada Forma entre nubes, además de un pequeño crucificado de gusto romanista. Las perillas en los salientes menores y las pirámides con esferillas de remate en los extremos principales de los brazos, completa su ornamento. La abstracción arquitectónica se vuelve a percibir en el nudo, en este caso cilíndrico, sobre ancho y panzudo gollete, y rematado por el casquete semiesférico, o lo que sería lo mismo, la tradicional macolla que también fue empleada por Francisco de Alfaro y Oña en el ejemplar de la parroquia de santa Cruz de Sevilla ${ }^{5}$. Su adorno se completa con pilastras terminadas en tornapuntas que delimitan los cuatro frentes rectangulares, decorados con un botón esmaltado entre foliáceas grabados, y las costillas de la base y la cubierta que también reciben esmaltes similares pero en disposición horizontal. Sin duda, un modelo de cruz manierista aceptado ya por la Iglesia local como prototipo contrarreformista, repitiéndose en otros ejemplares contemporáneos como los de la parroquia mayor de Lebrija, del orfebre Francisco Ortiz Pérez y el anónimo de la iglesia de santa Ana de Triana ${ }^{6}$.

Desafortunadamente nos gustaría contar con más datos sobre el autor de esta magnífica pieza, el cual no aparece en los repertorios biográficos de plateros publicados. De hecho, desde esta actividad en Marchena, hay que esperar cinco años para volver a tener noticias sobre su existencia. Éstas se reducen al poder, fechado el 2 de marzo de 1607, que otorgó a Juan de Portillo y Diego de Arana, procuradores de la Real Audiencia para que lo representasen en unos pleitos; y a la carta de pago, del 8 de marzo de ese mismo año, para recoger por escrito los dineros recibidos por Esteban de León, alguacil de la Real Audiencia, por varios trabajos de aderezo de una espada y pletinas de plata, así como de un relicario de oro con granates y otras piezas de plata ${ }^{7}$. Después se pierde su rastro entre la documentación que hasta el día de hoy hemos consultado. A pesar de ello, y sin apoyo documental que lo sustente, quizás podamos estar ante un familiar de otro

5 SANTOS, Antonio: "La Vida y la Obra del Platero Francisco de Alfaro y Oña (1572-1602)", Laboratorio de Arte, 17, 2004, pp. 413-429

${ }^{6}$ Sobre la cruz manierista de esta época, siguiendo el modelo de Merino y Alfaro ver SANZ, María Jesús: "La cruz procesional en la últimas décadas del siglo XVI: origen del cambio tipológico", en Estudios de platería: San Eloy 2002, 2002, pp. 427-440; SANTOS, Antonio. "La cruz patriarcal de Francisco Merino y su inmediata influencia en Andalucía y Castilla", Laboratorio de Arte, 25, vol. I, 2013, pp. 235-253; VARAS, Manuel: "Fuentes Arquitectónicas del Orfebre Francisco Merino. la Cruz Patriarcal de la Catedral de Sevilla", Annuarium Sancti Iacobi. 1, vol. 1, 2013, pp. 399-414. Sobre las cruces de Lebrija y Triana: SANZ, María Jesús: La orfebrería sevillana del Barroco. Sevilla, 1977, t. II, p. 111; BELLIDO AHUMADA, José: La patria de Nebrija (Noticias históricas). Los Palacios, 1985, p. 231.

${ }^{7}$ AHPSe. SPNSe.: Legajo 10873, oficio 17, libro $2^{\circ}$ 1607, ff. 774 recto-vuelto, 882 recto 
platero destacado de la época, Bartolomé del Castillo, autor del templete eucarístico de Alcalá de los Gazules (Cádiz) y padre del también orfebre Juan del Castillo, platero catedralicio entre los años 1655 y $1660^{8}$. Pero habrá que esperar a futuras averiguaciones para corroborar este parentesco y profundizar en la vida de un orfebre cuya obra conservada bien justifica esta investigación.

Fecha de recepción: 2 de septiembre de 2014

Fecha de aceptación: 28 de noviembre de 2014

${ }^{8}$ GESTOSO, José: Ensayo de un diccionario de los artifices que florecieron en Sevilla desde el siglo XIII al XVIII inclusive. Sevilla, 1900, vol. II, p. 165; DE BAGO Y QUINTANILLA, Miguel: "Aportaciones Documentales", en Documentos para la Historia del Arte en Andalucía, t. I, Sevilla, 1927, pp. 194-199; ILLÁN, Magdalena, VALDIVIESO, Enrique: Noticias artísticas de platería sevillana del Archivo Farfán Ramos. Siglos XVI-XVII y XVIII. Sevilla, 2006, pp. 51-53; QUILES, Fernando: Teatro de la Gloria. El universo artístico de la Catedral de Sevilla en el Barroco. Sevilla, 2007, pp. 361-362. 


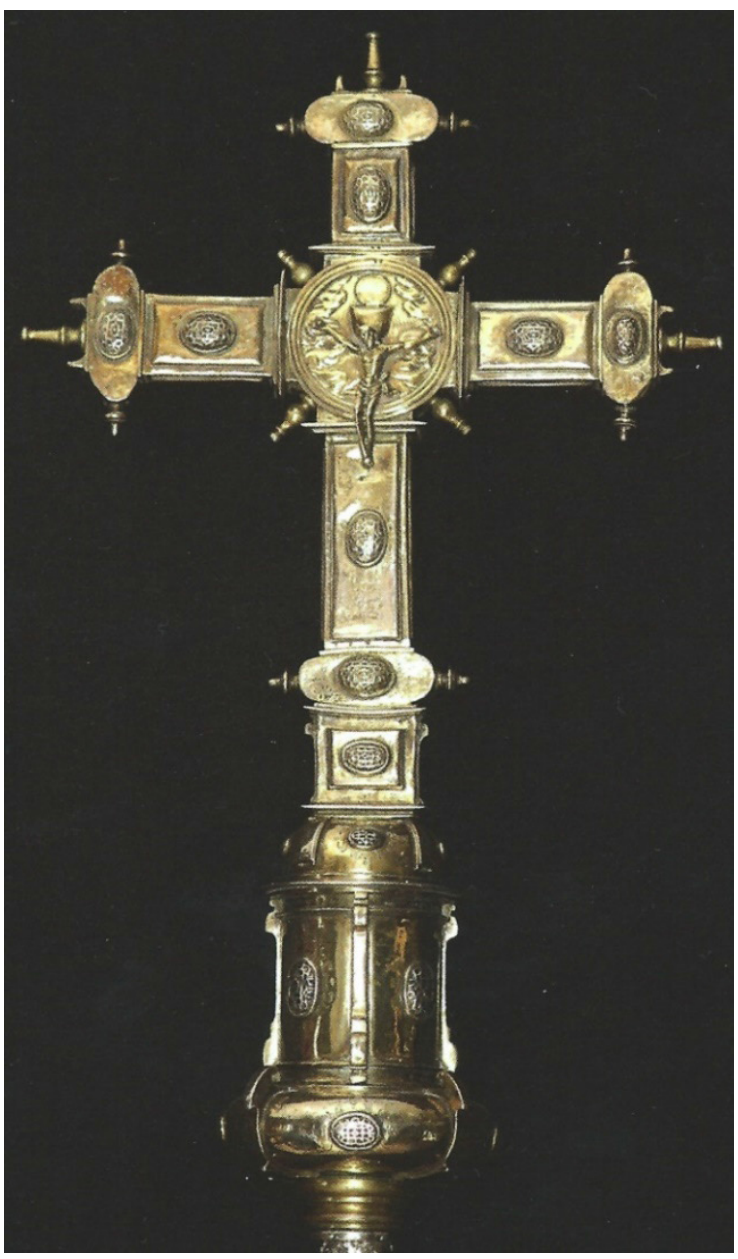

Figura 1. Cruz alzada de la Hermandad Sacramental de la parroquia de san Juan Bautista de Marchena. Antón del Castillo, 1602. 